\title{
SENSITIVITY ANALYSIS OF THE STRESS STATE IN SHELL COURSES OF WELDED TANKS FOR OIL STORAGE
}

\author{
Zdeněk KALA $^{\mathrm{a}}$, Jakub GOTTVALD ${ }^{\mathrm{b}}$, Jakub STONIŠb ${ }^{\mathrm{b}}$, Abayomi OMISHORE ${ }^{\mathrm{a}}$ \\ anstitute of Structural Mechanics, Faculty of Civil Engineering, Brno University of Technology, \\ Veveři Str. 95, 60200 Brno, Czech Republic \\ ${ }^{b}$ VÍTKOVICE ÚAM, Inc, Mezírka 775/1, 60200 Brno, Czech Republic
}

Received 12 April 2014, accepted 01 June 2014

\begin{abstract}
The paper deals with the analysis of reliability and safety of a welded tank for the storage of oil, which is located in the Czech Republic. The oil tank has a capacity of 125 thousand cubic meters. It is one of the largest tanks of its kind in the world. Safety is ensured by a steel outer intercepting shell and a double bottom. The tank was modelled in the programme ANSYS. The computational model was developed using the finite element method - elements SHELL181. A nonlinear contact problem was analysed for the simulation of the interaction between the bottom plate and foundation. The normative approach in design and check of tanks according to standards API 650, ČSN EN 14015, EEMUA 159 and API 653 is mentioned. The dominant loading of the filled tank is from oil. The normative solution is based on the shell theory, which considers constant wall thickness. For real tanks sheet thicknesses of individual courses increase with increasing depth. Stochastic sensitivity analysis was used to study the effect of the variability of the thickness of the $\mathrm{i}^{\text {th }}$ course on the stress of adjacent courses. The Latin Hypercube Sampling method was implemented during analysis.
\end{abstract}

Keywords: reliability, safety, crude oil, steel, plate, tank, course, shell, ANSYS, stress, thickness, stiffness.

\section{Introduction}

Czech Republic has crude oil reserves for 94 days. The EU law requiring reserves for 90 days is thus met. Crude oil is brought into the Czech Republic via the Druzhba pipeline from Russia and the IKL pipeline from Bavarian Vohburg near Ingolstadt (where it is transported via the TAL pipeline from the region of the Caspian Sea, the Middle East and North Africa). Given the current situation in Ukraine and Crimea oil supply to the Czech Republic is monitored daily and the current state of reserves is evaluated.

Storage of the oil is in large cylindrical tanks, which were constructed not far from the village Nelahozeves. The tank illustrated in Figure 1 has a height of $27 \mathrm{~m}$ and a capacity of 125 thousand cubic meters. It is one of the largest storage tanks of its kind in the world.

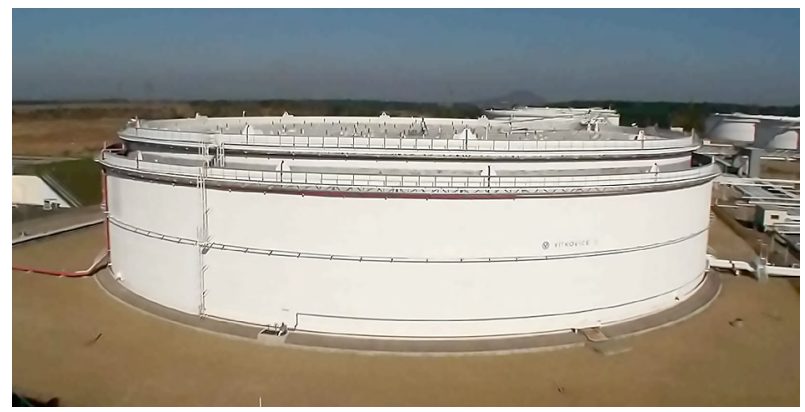

Fig. 1. Welded tank for oil storage

There is a floating roof on the surface of the stored liquid (crude oil), which prevents evaporation of the oil. The floating pontoon roof moves along with the oil level in the tank. In a drained tank the floating roof rests on supports on the bottom of the tank, see Figure 2.

Corresponding author:

Z. Kala E-mail: kala.z@fce.vutbr.cz 


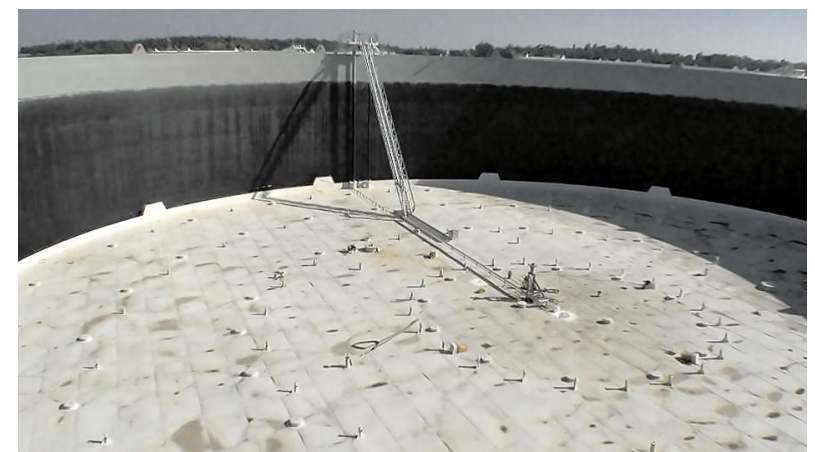

Fig. 2. Floating roof in a drained tank

A full tank contains crude oil worth 57 million Euros. The actual tank type is acc. to international standards and the structural design of some of its parts is based on calculations carried out in the Czech Republic. Safety is ensured by its double steel cover steel outer intercepting shell and double bottom, see Figure 3. The steel outer intercepting shell is a safety mechanism intended to prevent the leakage of oil in case of damage to the inner shell (tank shell). The structural design consisting of the shell of steel outer intercepting shell and steel tank allows the erection of tanks closer to each other leading to savings on otherwise needed space for containment dikes.

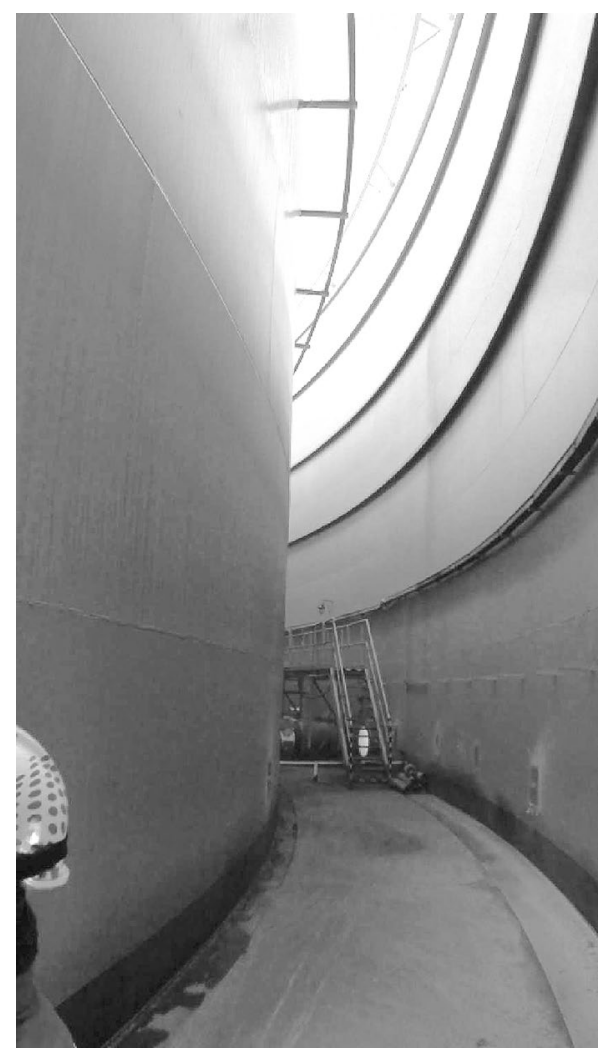

Fig. 3. Tank and interception shells
Fire is one of the biggest operation safety risks of oil storage tanks. In the event of fire the tanks are extinguished with foam from the fire protection system, which is part of the tank. Fire is most probable to occur between the roof and the tank, which is fitted with special rubber double seal.

Oil is a strategically important raw material and thus increased attention should be paid to its transportation and storage. The dominant load of a cylindrical tank is the loading of its inner shell by hydrostatic pressure of the oil. Plate thicknesses of individual courses increase from the top downwards. The plate of the bottom shell course has the greatest thickness because the hydrostatic pressure is highest there. Plate thicknesses of individual courses are designed acc. to standards API 650 or ČSN EN 14015, standards EEMUA 159 and API 653 are for inspection (service). The design criteria of the mentioned standards are based on the allowable stress design concept.

\section{Allowable stress method}

The principal factor, which determines the thickness of the tank shell, is the internal loading caused by the head of liquid. The minimum acceptable thickness for welded tank shells may be calculated from the following formula listed in standard EEMUA 159 for the basic control of tank shells:

$$
t_{\min }=\frac{D}{20 \cdot S \cdot E}(98 \cdot W \cdot(H-0.3)+P),
$$

where: $t_{\text {min }}$ is the minimum acceptable thickness in $\mathrm{mm}$ from the above equation (1), which should not be less that $2.5 \mathrm{~mm}$ or $50 \%$ of the original shell plate thickness, whichever is greater. This applies to inspections. The thickness is limited to $40 \mathrm{~mm}$ in design (reason for the introduction of maximum thickness is fear of brittle fracture for larger thicknesses and acc. to the tank diameter from 5 to $12 \mathrm{~mm}$ (minimum thickness for stability); $D$ is the nominal diameter [m]; $H$ is the height from the point under consideration to the maximum filling height $[\mathrm{m}]$, see Figure $2 ; W$ specify gravity of the content; $P$ design vapour pressure in mbar; $S$ maximum allowable stress in MPa; $E$ original joint efficiency for the tank; $E=0.85$ if original $E$ is unknown; $E=1.0$ when evaluating the retirement thickness in a corroded plate, when away from welds or joints by at least the greater of $25 \mathrm{~mm}$ or twice the plate thickness.

A similar formula is given in standards API 650, ČSN EN 14015 and API 653. The design and control 
formulae in the mentioned standards are based on the shell theory, which considers constant wall thickness. Therefore the stress in (1) is evaluated $0.3 \mathrm{~m}$ from the bottom edge of the respective course at the point where the shell theory can be applied. This method of calculation is known as the "one foot" method (Long, Garner 2004).

\section{Analysis of the stress state using the ANSYS program}

The stress and deformation of a fully filled tank, which is shown in Figure 1, was analysed. The tank has nine courses. The radius of the tank is $42.235 \mathrm{~m}$, height form the bottom to the oil level is $22.3 \mathrm{~m}$, and height of the tank is $24.0 \mathrm{~m}$. The nominal heights of individual courses from the bottom to the top: $2.2 \mathrm{~m}, 2.4 \mathrm{~m}$, $2.4 \mathrm{~m}, 2.8 \mathrm{~m}, 2.8 \mathrm{~m}, 2.85 \mathrm{~m}, 2.85 \mathrm{~m}, 2.85 \mathrm{~m}, 2.85 \mathrm{~m}$. The nominal thickness of individual courses from bottom to top: $39 \mathrm{~mm}, 35 \mathrm{~mm}, 30 \mathrm{~mm}, 26 \mathrm{~mm}, 22 \mathrm{~mm}$,
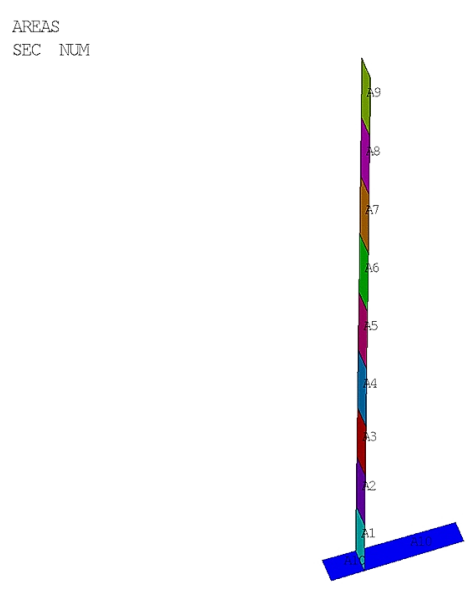

Fig. 4. Model A

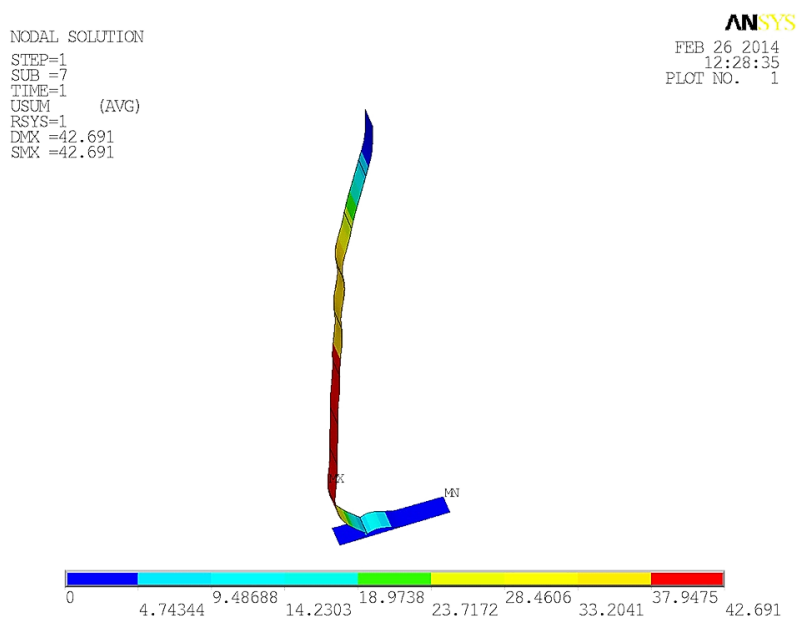

Fig. 5. Total deformation of model A [mm]
$17 \mathrm{~mm}, 12 \mathrm{~mm}, 11 \mathrm{~mm}, 10 \mathrm{~mm}$. The tank is made of steel grade S355 apart from the top two courses, which are made of steel S235. The density of oil is considered as $880 \mathrm{kgm}^{-3}$.

The computational model was developed in the ANSYS programme. Four models A, B, C and D were developed. The model is located in a cylindrical coordinate system, where axis $Z$ is the axial direction (cylinder axis $-\mathrm{Z}$ coincides with the axis of the tank shell), axis $X$ is the radial direction and axis $Y$ is the circumferential direction. A sector of part of the tank of angle $1^{\circ}$ was modelled. Meshing was performed using elements SHELL181. Models A and B (Figs 4 to 6) were modelled from part of the tank bottom. Placement on the foundations was simulated as a contact problem. For models C and D (Figs 7 to 9) connection of the shell to the bottom of the tank was substituted by boundary conditions (fixed end for $\mathrm{C}$ and rotation about the circumferential axis was allowed for D).

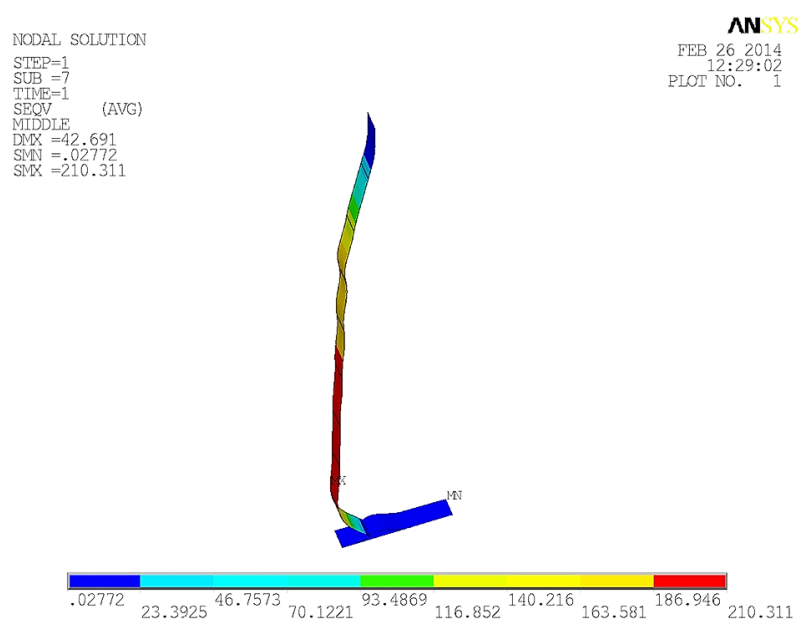

Fig. 6. Membrane reduced stress acc. to von Mises of model A [MPa]
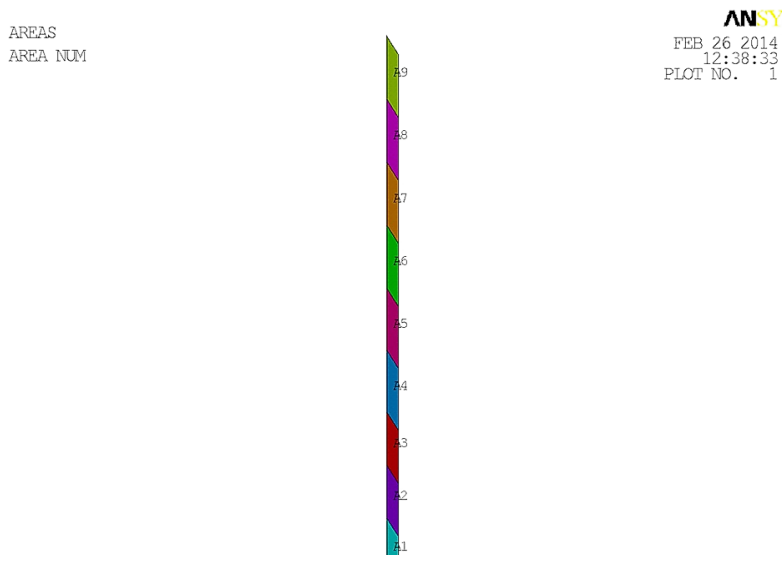


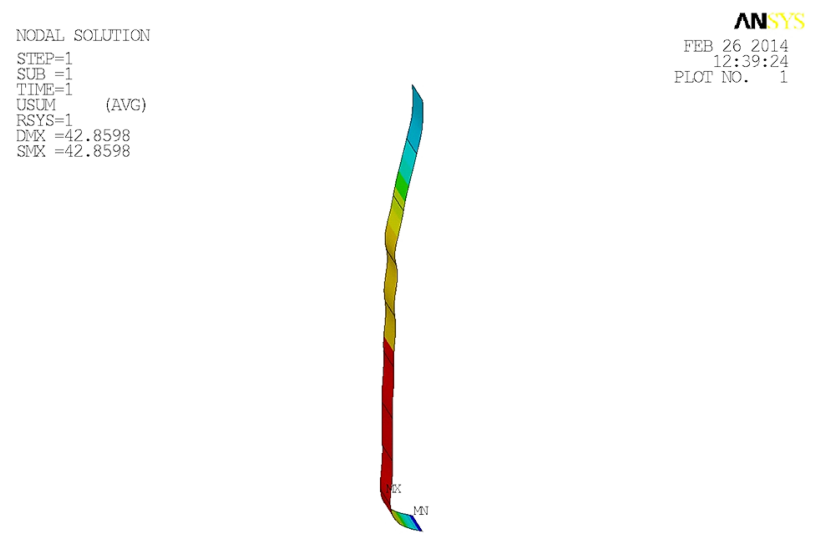

$4.7622^{9.52441} 14.2866^{19.0488} 23.811^{28.5732} 33.3354^{38.0976} 42.8598$

Fig. 8. Total deformation of model D [mm]

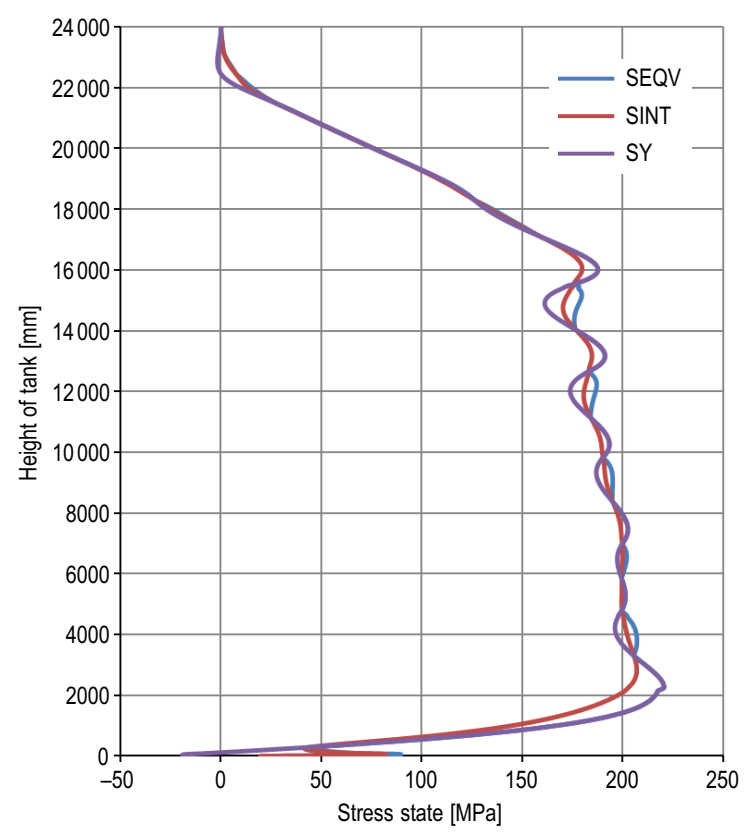

Fig. 10. Membrane stress distribution of model A

Models A, C and D have their shell plates aligned to the centreline. Model B has shell plates aligned to the inner side of the plate.

Stress distribution along the height of the tank was studied: SEQV is the reduced stress acc. to von Mises, SINT is the reduced stress acc. to Tresca $\left(\tau_{\max }\right)$, $\mathrm{SY}$ is the circumferential stress.

\section{Stochastic sensitivity analysis}

In further studies the effects of the variability of the plate thickness and Young's modulus of the course on stress along the height of the tank will be analysed. The effect of loading due to hydrostatic pressure on
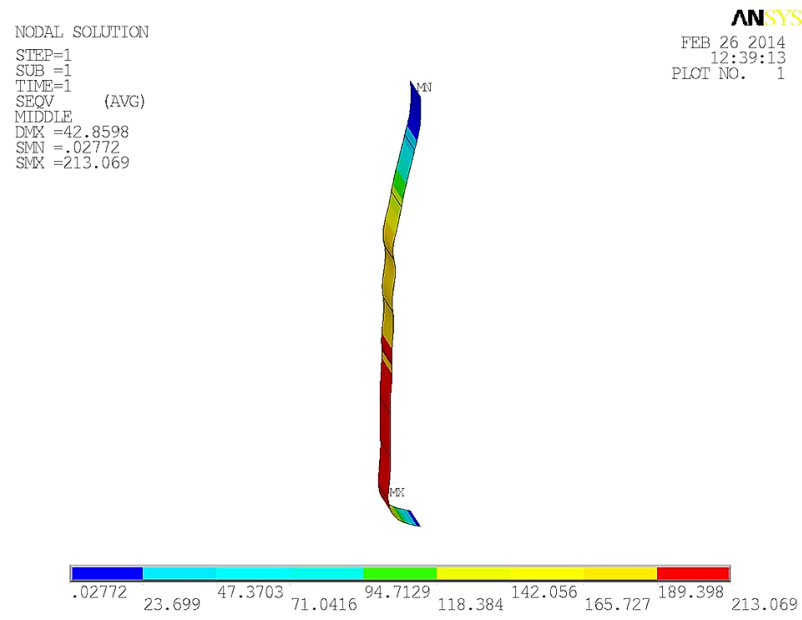

Fig. 9. Membrane reduced stress acc. to von Mises of model D [MPa]

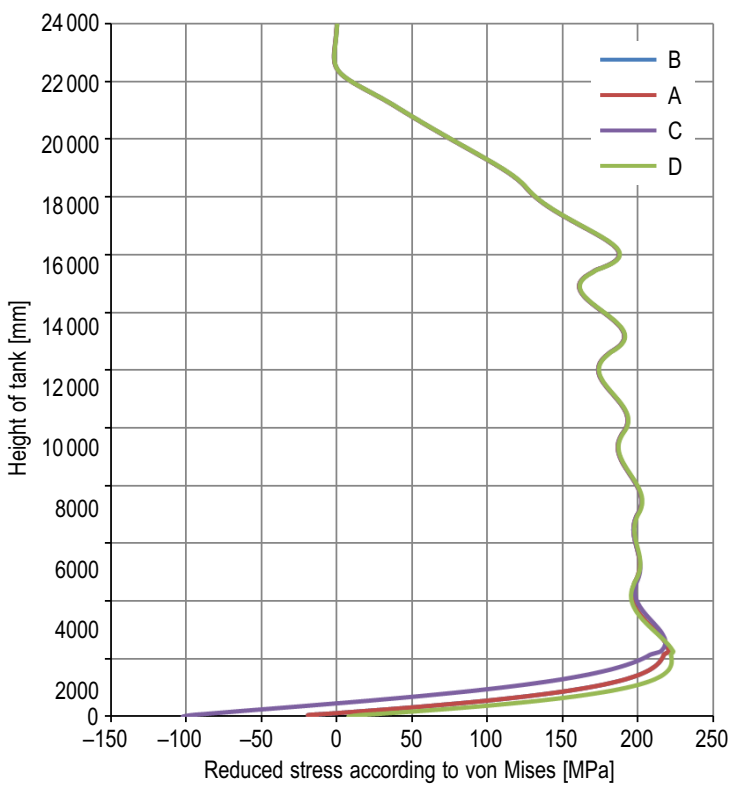

Fig. 11. Comparison of reduced membrane stress acc. to von Mises acc. to model type

the walls of the full tank on Mises stress is studied. In order to study the effect of the stiffness of one course on the stress in adjacent courses, the thicknesses of the courses and Young's modulus were considered as random quantities, see Table 1. Other input material and geometric characteristics are considered with values from the previous chapter.

Input random quantities were considered acc. to results of experimental research (Melcher et al. 2004; Kala et al. 2009; Soares 1988). It may be noted that the data of experimental research has been the source for a number of reliability studies, see e.g. (Kala 2012; Gottvald, Kala 2012). Analysis was performed using 100 
simulation runs of Latin Hypercube Sampling method (LHS), which is a method of type Monte Carlo (McKey et al. 1979; Iman, Conover 1980).

It was observed that the random variability of Young's modulus has a minimum effect on the stress in the tank. The effect of the random variability of the thickness of the plate of the $\mathrm{i}^{\text {th }}$ course on the stress along the height of the tank is depicted in Figure 12. A negative correlation means that with increasing plate thickness the stress decreases at the point at which the correlation coefficient is plotted, see Figure 12. Results for the top course are irrelevant because they are located where the stress is zero; therefore they are not shown in Figure 12.

Table 1. Input random quantities

\begin{tabular}{|c|c|c|c|c|}
\hline No. & Symbol & Course & Mean value & Standard deviation \\
\hline 1 & $t_{1}$ & bottom & $39 \mathrm{~mm}$ & $1.56 \mathrm{~mm}$ \\
\hline 2 & $t_{2}$ & 1 & $35 \mathrm{~mm}$ & $1.4 \mathrm{~mm}$ \\
\hline 3 & $t_{3}$ & 2 & $30 \mathrm{~mm}$ & $1.2 \mathrm{~mm}$ \\
\hline 4 & $t_{4}$ & 3 & $26 \mathrm{~mm}$ & $1.04 \mathrm{~mm}$ \\
\hline 5 & $t_{5}$ & 5 & $22 \mathrm{~mm}$ & $0.88 \mathrm{~mm}$ \\
\hline 6 & $t_{6}$ & 6 & $17 \mathrm{~mm}$ & $0.68 \mathrm{~mm}$ \\
\hline 7 & $t_{7}$ & 7 & $12 \mathrm{~mm}$ & $0.48 \mathrm{~mm}$ \\
\hline 8 & $t_{8}$ & 8 & $11 \mathrm{~mm}$ & $0.44 \mathrm{~mm}$ \\
\hline 9 & $t_{9}$ & top & $10 \mathrm{~mm}$ & $0.4 \mathrm{~mm}$ \\
\hline 10 & $E_{1}$ & bottom & $210 \mathrm{GPa}$ & $12.6 \mathrm{GPa}$ \\
\hline 11 & $E_{2}$ & 1 & $210 \mathrm{GPa}$ & $12.6 \mathrm{GPa}$ \\
\hline 12 & $E_{3}$ & 2 & $210 \mathrm{GPa}$ & $12.6 \mathrm{GPa}$ \\
\hline 13 & $E_{4}$ & 3 & $210 \mathrm{GPa}$ & $12.6 \mathrm{GPa}$ \\
\hline 14 & $E_{5}$ & 5 & $210 \mathrm{GPa}$ & $12.6 \mathrm{GPa}$ \\
\hline 15 & $E_{6}$ & 6 & $210 \mathrm{GPa}$ & $12.6 \mathrm{GPa}$ \\
\hline 16 & $E_{7}$ & 7 & $210 \mathrm{GPa}$ & $12.6 \mathrm{GPa}$ \\
\hline 17 & $E_{8}$ & 8 & $210 \mathrm{GPa}$ & $12.6 \mathrm{GPa}$ \\
\hline 18 & $E_{9}$ & top & $210 \mathrm{GPa}$ & $12.6 \mathrm{GPa}$ \\
\hline & & & & \\
\hline
\end{tabular}

It may be added that correlation indicates dependence, but the contrary is not true. Sensitivity analysis based on correlation requires that the output is monotonically dependent on each input variable. This is a problem of models of the so-called "black box" type where using simple statistical analysis of the LHS method cannot detect cases of non-correlation or "false insensitivity", and which need additional studies confirming the monotonic dependence of the output on the input. Correlation as an indicator of sensitivity can be used in transparent models, which is the case of the presented study or studies for e.g. (Melcher et al. 2009).

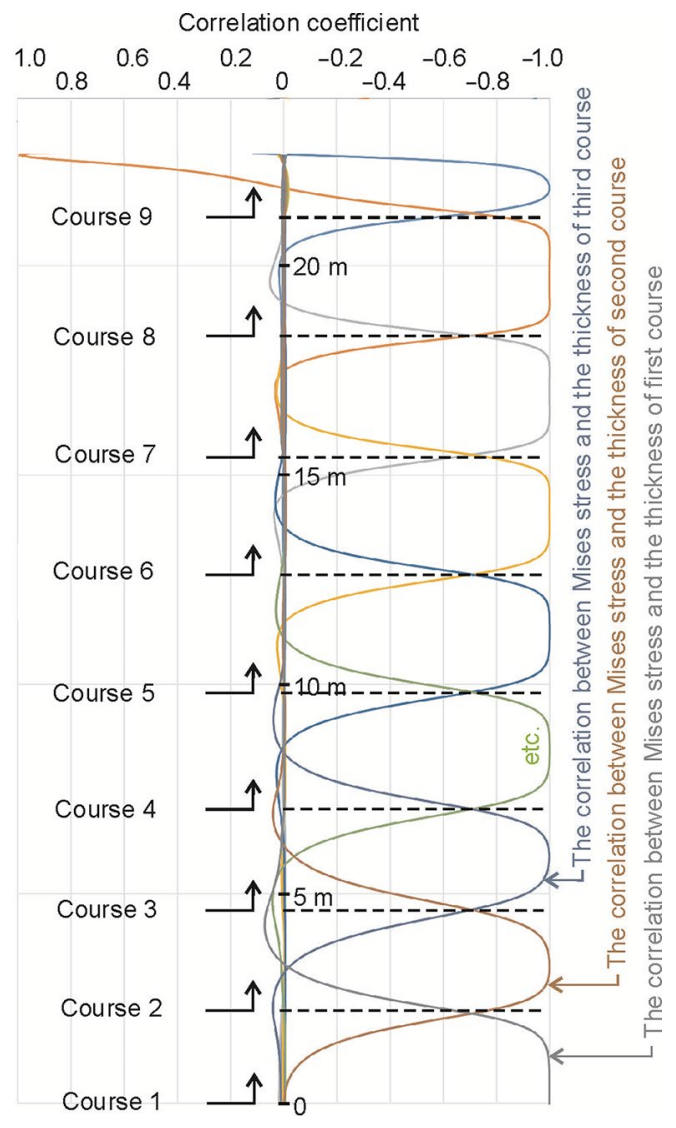

Fig. 12. Correlation between thickness $t_{i}$ and von Mises stress state SEQV for model A

\section{Conclusions}

From the analysis of the stress state along the height of the tank it was found that the reduced stress acc. to von Mises (SEQV), reduced stress acc. to Tresca (SINT) and circumferential stress SY have approximately the same course, see Figure 10. Stress SY has the relatively highest values and displays the relatively most erratic behaviour. These results were evaluated for model A, for which part of the bottom was also modelled. Comparison of stress SEQV of all four models showed that the effect of the boundary conditions of the stiffness of the bottom is not significant with the exception of the first course, where the difference was up to $100 \mathrm{MPa}$. It is debatable if modelling the joint of the wall-bottom using a hinge is sufficient for the analysis of the stress of the first course.

Sensitivity analysis based on the evaluation of the correlation between the random plate thicknesses and stress SEQV showed that the variability of the thickness of one course affects the stress in adjacent courses, see Figure 12. This effect is more significant in the bottom courses. The load is partially transferred to the 
adjacent courses due to differences in the stiffness of adjacent courses. The stiffness of adjacent courses has the greatest influence on stress in the bottom courses. The influence zone is higher for the bottom courses than the upper courses. Equation (1), which is the basis of reliability assessment of standards API 650 and ČSN EN 14015 is based on the assumption that the stiffness of one course has no influence on the stress in adjacent courses. This assumption is only partially true for real tanks.

The obtained results of the stochastic sensitivity analysis open the debate on the detailed modelling of tanks using the finite element method. The ANSYS programme offers a wide range of shell finite elements, which are suitable for the analysis of stress of thin steel plates. Generally, the more detailed the applied computational model, the more reliable are the conclusions, which are obtained through the analysis of stress. It is always necessary to be aware of conventional and practically verified methods used for design and assessment, which are often the basis of reliable standardized procedures.

\section{Acknowledgement}

The article was elaborated within the framework of projects of TAČR TA01020307 and GAČR 14-17997S.

\section{References}

API 650 American Petroleum Institute. 2013. Welded Tanks for Oil Storage, Twelfth Edition, Includes Errata.

API 653 American Petroleum Institute. 2009. Tank inspection, repair, alteration, and reconstruction. Washington, DC: API Publishing Services.

ČSN EN 14015: 2005. Specification for the design and manufacture of site built, vertical, cylindrical, flat-bottomed, above ground, welded, steel tanks for the storage of liquids at ambient temperature and above. ČNI - Adopted European Standard.

EEMUA 159. Users guide to the inspection, maintenance and repair of aboveground vertical cylindrical steel storage tanks. 2003.

Gottvald, J.; Kala, Z. 2012. Sensitivity analysis of tangential digging forces of the bucket wheel excavator SchRs 1320 for different terraces, Journal of Civil Engineering and Management 18(5): 609-620.

http://dx.doi.org/10.3846/13923730.2012.719836

Iman, R. C.; Conover, W. J. 1980. Small sample sensitivity analysis techniques for computer models with an application to risk assessment, Communications in Statistics - Theory and Methods 9(17): 1749-1842. http://dx.doi. org/10.1080/03610928008827996

Kala, Z. 2012. Geometrically non-linear finite element reliability analysis of steel plane frames with initial imperfections, Journal of Civil Engineering and Management 18(1): 81-90. http://dx.doi.org/10.3846/13923730.2012.655306

Kala, Z.; Melcher, J.; Puklický, L. 2009. Material and geometrical characteristics of structural steels based on statistical analysis of metallurgical products, Journal of Civil Engineering and Management 15(3): 299-307.

http://dx.doi.org/10.3846/1392-3730.2009.15.299-307

Long, B.; Garner, B. 2004. Guide to storage tanks and equipment. Wiley. 588 p. ISBN-10:1860584314.

McKey, M. D.; Conover, W. J.; Beckman, R. J. 1979. A comparison of the three methods of selecting values of input variables in the analysis of output from a computer code, Technometrics 21(2): 239-245.

Melcher, J.; Kala, Z.; Holický, M.; Fajkus, M.; Rozlívka, L. 2004. Design characteristics of structural steels based on statistical analysis of metallurgical products, Journal of Constructional Steel Research 60(3-5): 795-808.

http://dx.doi.org/10.1016/S0143-974X(03)00144-5

Melcher, J.; Škaloud, M.; Kala, Z.; Karmazínová, M. 2009. Sensitivity and statistical analysis within the elaboration of steel plated girder resistance, Advanced Steel Construction 5(2): $120-126$.

Soares, G. C. 1988. Uncertainty modelling in plate buckling, Structural Safety 5(1): 17-34.

http://dx.doi.org/10.1016/0167-4730(88)90003-3

Zdeněk KALA. Professor, PhD at the Department of Structural Mechanics, Brno University of Technology, Faculty of Civil Engineering. Co-author of 14 books, 3 textbooks and more than 180 scientific papers (120 published abroad). Research interests: elastic-plastic analysis, stability problems, sensitivity analysis and optimization of steel and steel-concrete structures including material and geometrical non-linearities, numerical methods in structural mechanics, and reliability methods.

Jakub GOTTVALD. PhD Director of the company VÍTKOVICE ÚAM Inc. A member of the Czech Society for Mechanics. The author and co-author of about 30 scientific papers. Research interests: applied mechanics, experimental and computational mechanics, FEM analyses of structures and results of In-Situ measurement verifications.

Jakub STONIŠ. Employee of the company VÍTKOVICE ÚAM Inc. Research interests: applied mechanics, experimental and computational mechanics, FEM analyses of steel structures.

Abayomi OMISHORE. PhD at the Department of Structural Mechanics, Brno University of Technology, Faculty of Civil Engineering. Author and co-author of more than 40 scientific papers. Research interests: uncertainty analysis and optimisation of structures, numerical methods in structural mechanics, reliability methods. 